CORRIGENDUM

doi:10.1038/nature10788

\title{
A reserve stem cell population in small intestine renders Lgr5-positive cells dispensable
}

Hua Tian, Brian Biehs, Søren Warming, Kevin G. Leong, Linda Rangell, Ophir D. Klein \& Frederic J. de Sauvage

Nature 478, 255-259 (2011).

In this Letter, two additional references ${ }^{32,33}$, which described stem-cell organization in the intestinal crypt, should have been cited after the first sentence of the main text: "Two types of stem cells have been described in the small intestine based on location and cycling dynamics ${ }^{1-4,32,33}$.". The references and their citations have been added to the PDF and HTML versions.

32. Potten, C. S., Gandara, R., Mahida, Y. R., Loeffler, M. \& Wright, N. A. The stem cells of small intestinal crypts: where are they? Cell Prolif. 42, 731-750 (2009).

33. Bjerknes, M. \& Cheng, H. The stem-cell zone of the small intestinal epithelium. I. Evidence from Paneth cells in the adult mouse. Am. J. Anat. 160, 51-63 (1981). 